\title{
Analyzing Competition In Pharmaceutical Sector - With A Case Study Of Albania
}

\author{
Lorena Balili, PhD Candidate \\ University of Tirana, Albania
}

doi: 10.19044/esj.2016.v12n15p132 URL:http://dx.doi.org/10.19044/esj.2016.v12n15p132

\begin{abstract}
Albanian pharmaceutical market is a stable and regulated market. With a status of an EU candidate country, it is essential to adopt and transpose EU directives with domestic regulation. The aim of this study is to provide a panorama regarding pharmaceutical sector, by reflecting the specific elements that influence the demand and supply of product. It will be followed by a brief description regarding three major regulatory aspects that affect the activity of companies operating in it. This study has two main pillars: Comparative analysis between Albania and Macedonia regarding the three main indicators of Health financing system; Competitiveness analysis, which consists in studying the competition between the constituent companies of the pharmaceutical sector in Albania. We calculate the fourfirm concentration ratio (CR4) and Herfindahl Hirschman Indexes (HHI). In the end we present the main findings from our study.
\end{abstract}

Keywords: Pharmaceutical sector, Competitiveness, Concentration ratio, Health expenditure, Albania

\section{Introduction}

Pharmacy practice in Europe, as a subject of study in itself, was organized in 1241. For thousands of years, empirical medicine and pharmacy were considered the same.

The pharmaceutical sector is a unique sector, which stands apart from the usual competition, for it is heavily regulated due to its critical importance to human welfare. To study the level of competition in this sector, one should necessarily analyze the demand and supply for the products offered in this market. On the demand side, apart from standard over-the counter medicine, we have a low level of individual consumers who exercise their freedom to choose between competing products based on features and relative prices. First, it can be argued with the low level of qualification of the customer to understand the pharmacological properties of these 
ingredients although the exact chemical composition of medicines is mandatorily printed on the packaging.

Second, the products in this sector have features that consumers can not evaluate before use and in some cases the characteristics become difficult to identify even after use since the effects of the medication may not be apparent for a long time. It is important to mention that the drugs included in the category of goods are based on medical advice. To a great extent, therefore, demand is driven by the prescribing behavior of healthcare providers.

As a result consumers are not necessarily price sensitive. Another phenomenon often occurs in which pharmacists can substitute drugs with others or can either make descriptions of drugs to patients who are unwilling to go to a doctor. This reflects a very large distance to the final consumers by the manufacturers. Given that, many of these products are essential for human welfare, even making the difference between life and death, consumers are not price sensitive and are willing to sacrifice other consumption needs in order to incur healthcare expenses.

Even in developed countries this findings are relevant, but the situation in Albania is particularly delicate because of the greater lack of awareness, information, education among consumers and limited coverage of health insurance.

Once described the main elements that influence demand, the supplyside pharmaceutical industry worldwide is dominated by a handful of firms; the dominance of reinforcing their market to the protection of the patent (for which they strive constantly to expand), higher advertising budgets and marketing led by health care providers who actually affect 'choice' of the customer. As pointed out in the pioneering study by Nanda and Khan (2006), there is the possibility of anti-competitive horizontal agreements at the level of producers as well as distributors, vertical agreements between producers and distributors in the supply chain and abuse of dominance arising out of patent protection.

In addition, one of the major factor that affect the development of each sector, is the process of regulatory development. Specifically, we will mention three key factors that influence this process in the pharmaceuticals: The first element is the licensing procedures for exercising the activity of wholesale, retail, import-export and production in the pharmaceutical sector. The second element relates to the statutory definition of reimbursable medicines and the third element relates to pricing policies.

In Albania, pharmaceutical sector is regulated by Law Nr. 105/2014 "On Drugs and Pharmaceutical Service"1

${ }^{1}$ This law is partly aligned with: Directive 2001/83 / EC of the European Parliament and 
This law establishes rules for the manufacture, placing on the market, import, export, marketing, use, marketing, quality control and inspection activities related to medicines for human use in the Republic of Albania, in order to ensure public health. This law applies to medicines for human use manufactured industrially, intended to be placed on the market in the Republic of Albania. Law nr.10383, 24.2.2011 "On compulsory insurance of health care in the Republic of Albania", lists reimbursable drugs as part of the compulsory insurance services. This package is compiled by determining among other things, the list of reimbursable drugs, as well as the extent of coverage of its drugs. The structure list of drugs is determined on the basis of the list of essential drugs, according to the classification INN (active principle of the drug), as defined by the World Health Organization.

The Council of Ministers nr.645 decision, 10.01.2014 "On the establishment and functioning of the price of drugs" regarding the price of medicines, sets that the price of drugs should be comparable to the price of five countries of the region (Macedonia, Greece, Italy, Serbia and Croatia) and can't be higher than in those countries. Drug Prices Commission verifies the documentation of imported medicines, carried out and submitted to the National Agency for Medicines and Medical Equipment, during the past 12 months. "The reference price for Albania" will be the lowest price of the following elements: a) the applied price of the five reference countries; b) the retail price of the drug in the origin country; c) the price of imported medicines in the Republic of Albania, during the past 12 months. The price of drugs on the market is controlled and based on CIF2 import prices declared by companies marketing authorization holder and on the basis of producer prices for medicines produced in the country, declared by the domestic producer.

\section{Health expenditure in Albania and Macedonia}

In Western Balkan countries, the transition from socialism to capitalism and democracy was less smooth than in other parts of Emerging Europe. Upon completion of this stage they passed huge challenges in complete reorganization of their respective economies toward transformation

Council dated November 6, 2001 "on the Community code relating to medicinal products for human use" Number CELEX: 32001L0083, Official Journal of the European Union, Series L, Nr.311, dated 28. 11. 2001, p 67-128, as amended. Directive 2001/20 / EC of the European Parliament and the Council of 4 April 2001 "on the approximation of laws, regulations and administrative provisions of the Member States relating to the implementation of good clinical practice in the conduct of clinical trials on medicinal products for human use" .

2 CIF import price "means the price" (Cost, Insurance, Freight - cost, insurance, transportation expense), designed to bar from the manufacturer or marketing authorization holder for crossing point of entry in the Republic of Albania. 
into market economies, building the institutions to support the market economy, liberalizing prices, and privatizing many state- and socially-owned enterprises. What becomes more apparent is that there is a strong orientation towards the European Union (EU) in the Western Balkan States (WBS), leading to an effort to align pharmaceutical legislation with EU directives. As of early 2016, the six countries of the Western Balkans - Albania, Bosnia and Herzegovina, FYR Macedonia, Kosovo, Montenegro and Serbia - face a formidable array of challenges.

Health expenditures constitute one of the most important issues for the economies of most countries of the world. Expenses on this regard, having a high exert on public budgets, measure government investments in well-being and health of their citizens. Based on this argument, and especially embraced by the priror history of civil war and by the global economic crisis in the last decade, this issue is even more challenging for most Balkan countries.

Below we examine three important indicators of health financing system for two countries of Western Balkan, Albania and Macedonia. More specifically, the reports are: 1 . Private expenditure on health as a percentage of total expenditure on health is a core indicator of health financing systems. This indicator contributes to understanding the relative weight of private entities in total expenditure on health. It includes expenditure from pooled resources with no government control, such as voluntary health insurance, and the direct payments for health by corporations (profit, non-for-profit and NGOs) and households. 2. General government expenditure on health as a percentage of total government expenditure contributes to understand the weight of public spending on health within the total value of public sector operations. It includes not just the resources channeled through government budgets but also the expenditure on health by extra-budgetary entities and notably the compulsory health insurance. 3. External resources for health as a percentage of total expenditure on health traces the financing flows from external sources who provide the funds to public and private financing agents. It includes in kind and in cash resources provided as loans and grants. This is, however, an indicator which refers to the origin of the resources used to purchase health services.

These data are generated from sources that World Health Organization (WHO), has been collecting for over ten years. The most comprehensive and consistent data on health financing is generated from national health accounts. ${ }^{3}$ In Albania, as shown in the table 1.dominates the

${ }^{3}$ The principal international references used are the EUROSTAT database, International Monetary Fund (IMF) international financial statistics; OECD health data. National sources include: National health accounts (NHA) reports, national accounts (NA) reports, general government (GG) accounts, public expenditure reviews (PER), notably social security and 
first report reflecting the high importance of private expenditure on health, reflecting an annual average rate of $19.5 \%$ higher than Macedonia. As for the second indicator we see a slightly higher and stable rate of Macedonia against Albania with an average annual rate of 5\% higher.
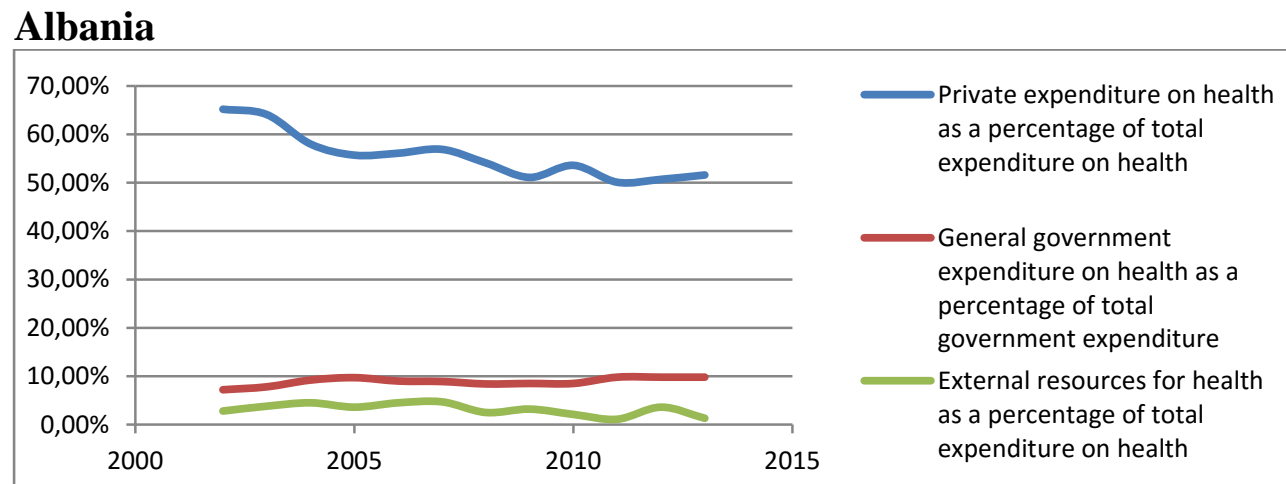

Table 1: Author's calculations based on the World Health Organization database

\section{Macedonia}

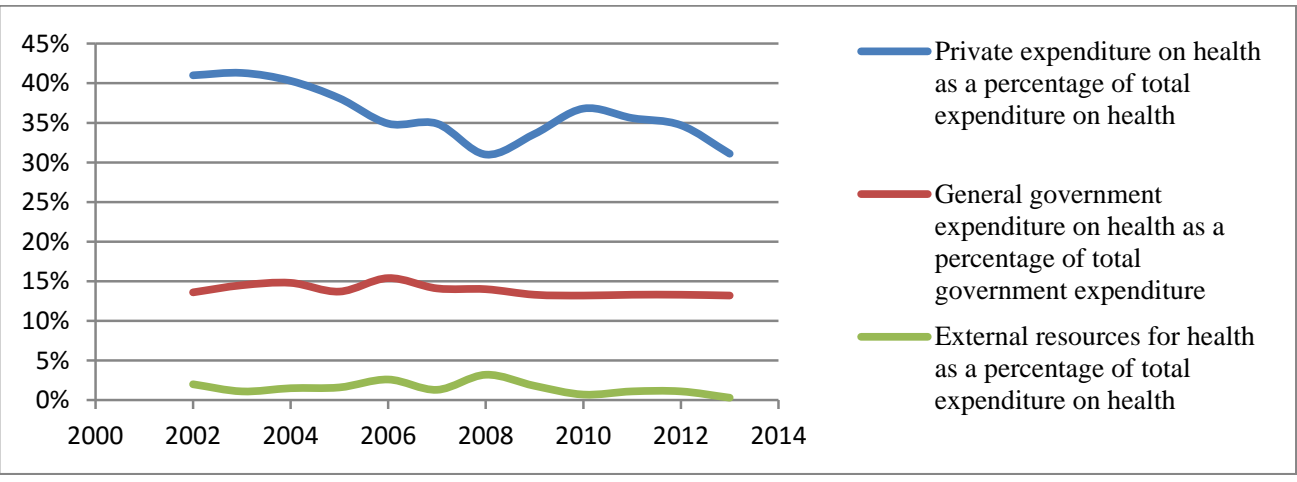

Table 2: Author's calculations based on the World Health Organization database

Despite the fact that in both countries the ratio is not high, it is concluded that in Albania the public expenditure allocated on health to the total government expenditure is lower than in Macedonia. It is shown that in Albania private expenditure on health was slightly higher than governmental. And finally, the third report calculated is approximately the same for both countries, with a slight fluctuation of $1.6 \%$ in average annual rate in Albania.

\section{Albanian pharmaceutical market and competitiveness study}

Albanian pharmaceutical market is a stable and regulated market. Currently there are about 100 pharmaceutical companies which are distributors of pharmaceutical products and only few of them are producers.

other health insurance compulsory agencies. 
About this total, 22 companies are counted as large tax payers, based on the internal regulations of the General Directorate of Tax where largest taxpayers (known as VIP), have a turnover of more than 250 million ALL (approximately 1.8 million EUR). The total sales of these companies for 2014 is 23,264,972,209 ALL $^{4}$. The dominance of these companies in the pharmaceutical market has been present for years. A part of the study is going to examine the degree of concentration of the four most important companies in the sector that indices of how fragmented the market is structured. Market structure varies from one extreme where perfect competition exists with many producers or sellers and easy market entry and exit. The other market extreme is a monopoly with effective barriers to entry of a competitor. The tendency toward a monopoly or a market with monopolistic characteristics or power is the focus of most studies using concentration indices.

The study will be based on the calculation of the four-firm concentration ratio (CR4) and Herfindahl Hirschman Indexes (HHI). The four-firm concentration ratio is an indicator of the size (as measured by output or sales) of the four largest firms within an industry, compared to the output of the entire industry. It is determined as follows:

$$
\mathrm{CR} 4=(\mathrm{X} 1+\mathrm{X} 2+\mathrm{X} 3+\mathrm{X} 4) / \mathrm{T}
$$

Where, $\mathrm{Xn}$ is the sale of the nth largest firm and $\mathrm{T}$ is the total sales of the industry.

The selected evaluation period is 2012- 2014. The calculation will be based on the identification of four companies which have a higher level of sales for the period selected. We make two assumptions to perform calculations. The first will be based on the actual sales of the 22 VIP companies in the pharmaceutical sector. And the second will be based on estimated data for all sector companies including actual data for 22 large companies and assuming a total sales level for 78 other companies as the maximum potential limit sales of 250 million.

In table 3 are presented the calculation of CR4 indicators for four biggest companies in the sector. Calculations are made on the factual data of 22 large companies.

\footnotetext{
${ }^{4}$ The data calculated by the author on the financial statements of companies stated in Regional Tax Directorate of Large Taxpayers
} 


\begin{tabular}{|c|c|c|c|}
\cline { 2 - 4 } \multicolumn{1}{c|}{} & Year 2012 & Year 2013 & Year 2014 \\
\hline Sales (company 1)/ total sales (\%) & 17.35 & 16.55 & 14.37 \\
\hline Sales (company 2)/ total sales (\%) & 9.94 & 12.33 & 13.04 \\
\hline Sales (company 3)/ total sales (\%) & 3.96 & 4.73 & 9.04 \\
\hline Sales (company 4)/ total sales (\%) & 10.53 & 9.64 & 7.81 \\
\hline Total & $41.78 \%$ & $43.25 \%$ & $44.26 \%$ \\
\hline Total Sales & 100 & 100 & 100 \\
\hline CR4 & $\mathbf{4 1 . 8 0 \%}$ & $\mathbf{4 4 . 3 0 \%}$ & $\mathbf{4 4 . 3 0 \%}$ \\
\hline
\end{tabular}

Table 3: Author calculations based on financial statement data

In table 4, is presented the calculation of CR4 for four biggest companies making sector estimates of total sector sales including factual data of 22 large companies (VIP) and estimated data for 78 other not large companies (non-VIP).

\begin{tabular}{|c|c|c|c|}
\hline 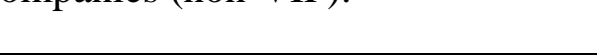 & Year 2012 & Year 2013 & Year 2014 \\
\hline $\begin{array}{c}\text { Sales (company 1)/ total estimated sales } \\
(\%)\end{array}$ & 8.95 & 8.95 & 7.82 \\
\hline $\begin{array}{c}\text { Sales (company } 2) / \text { total estimated sales } \\
(\%)\end{array}$ & 5.13 & 6.67 & 7.1 \\
\hline $\begin{array}{c}\text { Sales (company } 3) / \text { total estimated sales } \\
(\%)\end{array}$ & 2.05 & 2.56 & 4.92 \\
\hline $\begin{array}{c}\text { Sales (company } 4) / \text { total estimated sales } \\
(\%)\end{array}$ & 5.44 & 5.21 & 4.25 \\
\hline Total & $21.56 \%$ & $23.39 \%$ & $24.08 \%$ \\
\hline Total estimated Sales & 100 & 100 & 100 \\
\hline CR4 & $21.56 \%$ & $23.39 \%$ & $24.08 \%$ \\
\hline
\end{tabular}

Table 4: Author calculations based on financial statement data and estimated data

As in the first case and the second case, the generated results indicate a low level of concentration between $0 \%-50 \%$ which reflects a position between perfect competition and oligopoly.

The Herfindahl- Hirschman Index provides a more complete picture of industry concentration than does the concentration ratio. The HHI uses the market shares of all the companies in the industry, and these market shares are squared in the calculation to place more weight on the larger companies. If there are $\mathrm{n}$ companies in the industry, the HHI can be expressed:

HHI $=10,000 *\left(\mathrm{~s}_{1}{ }^{2}+\mathrm{s}_{2}{ }^{2}+\mathrm{s}_{3}{ }^{2}+\ldots .+\mathrm{s}_{\mathrm{n}}{ }^{2}\right)$

Where $s_{i}$ is the market share of the $i^{\text {th }}$ company

The calculations for the three years are given in the following tables for 100 companies of the sector. 


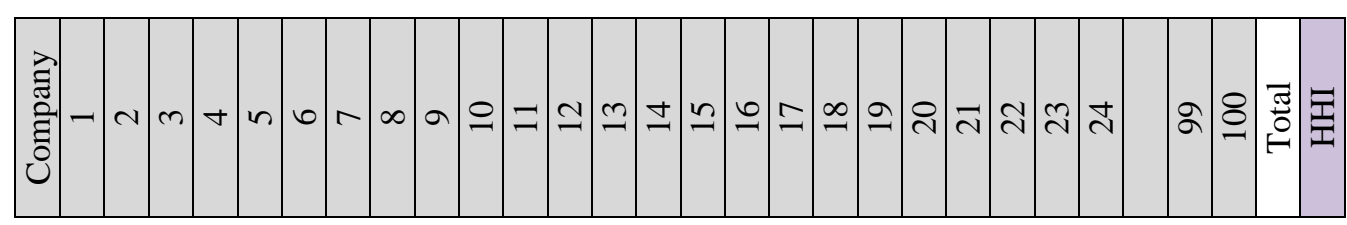

Year 2014

\begin{tabular}{|c|c|c|c|c|c|c|c|c|c|c|c|c|c|c|c|c|c|c|c|c|c|c|c|c|}
\hline 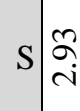 & & 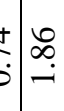 & 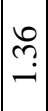 & 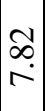 & 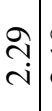 & $\begin{array}{l}\text { 원 } \\
\vec{i}\end{array}$ & 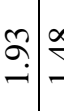 & & 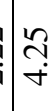 & $\stackrel{m}{\vec{N}}$ & & $\underset{0}{0}$ & نب & $\stackrel{6}{6}$ & $\frac{1}{2}$ & \begin{tabular}{c|c}
\multirow{2}{*}{} \\
$\dot{\sim}$
\end{tabular} & $\mid \begin{array}{l}0 \\
0 \\
0\end{array}$ & $\begin{array}{l}9 \\
0 \\
0 \\
0\end{array}$ & & 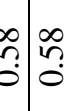 & $\left|\begin{array}{c}\infty \\
1 \\
0 \\
0\end{array}\right|$ & ch & & \\
\hline & & 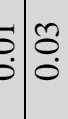 & م. & $\mid \begin{array}{l}0 \\
0\end{array}$ & $\begin{array}{l}0 \\
0 \\
0 \\
0\end{array}$ & $\begin{array}{l}\text { d. } \\
\dot{0}\end{array}$ & $\begin{array}{l}\dot{0} \\
0\end{array}$ & & $\dot{3}$ & 0. & & & & 0 & 0 & 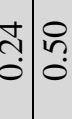 & $\mid \begin{array}{l}-1 \\
0 \\
0\end{array}$ & $\begin{array}{l}8 \\
0 \\
0\end{array}$ & $\left(\begin{array}{l}8 \\
0 \\
0\end{array}\right.$ & $\stackrel{8}{8}: \stackrel{8}{\circ}$ & 8: & $\stackrel{8}{8}$ & & \\
\hline
\end{tabular}

Year 2013

\begin{tabular}{|c|c|c|c|c|c|c|c|c|c|c|c|c|c|c|c|c|c|c|c|c|c|c|c|c|}
\hline $\mathrm{s} \underset{\sim}{\stackrel{\mathrm{v}}{\mathrm{i}}}$ & $\begin{array}{l}\infty \\
\infty \\
0 \\
0\end{array}$ & & 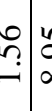 & c & ก & & 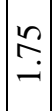 & 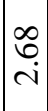 & \begin{tabular}{|l}
$\vec{\sim}$ \\
$\dot{\omega}$
\end{tabular} & 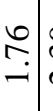 & 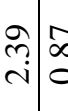 & & $\mid \begin{array}{l}n \\
0 \\
0 \\
0\end{array}$ & ${ }_{j}$ & & & $\begin{array}{c}0 \\
0 \\
0\end{array}$ & & & & & ํํㅇ & & \\
\hline & $\begin{array}{l}0 \\
\stackrel{2}{8} \\
0 \\
0\end{array}$ & 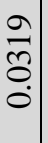 & 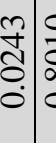 & & ta & & 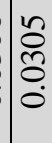 & $\begin{array}{l}\vec{N} \\
\hat{\tilde{O}} \\
0 \\
0\end{array}$ & 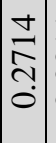 & $\begin{array}{l}\overrightarrow{\mathrm{m}} \\
\stackrel{0}{0} \\
0\end{array}$ & $\begin{array}{ll}-1 & \\
\hat{2} & \\
0 \\
0\end{array}$ & 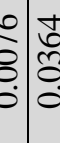 & 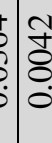 & I & & & 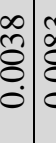 & $\begin{array}{l}: \\
:\end{array}$ & \begin{tabular}{l}
2 \\
\hdashline \\
\hdashline \\
0
\end{tabular} & 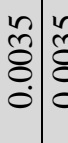 & & 낭 & & 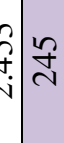 \\
\hline
\end{tabular}

Year 2012

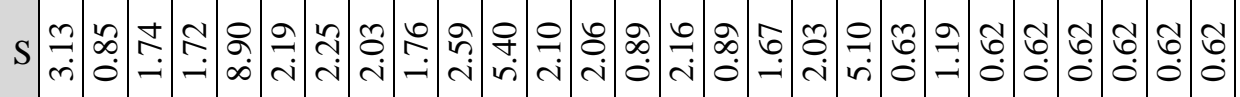

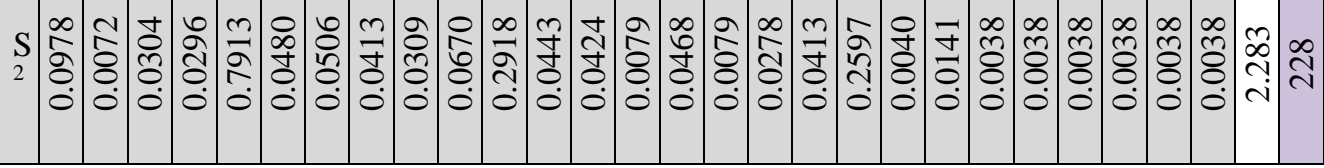

Table 5: Author calculations based on financial statement data and estimated data

We note that for 22 larger companies are using real data taken from actual financial statement of companies, for smaller ones we are assuming a maximum potential level sales of 250 million ALL. Choosing this limit helps us to determine the potential level of competitiveness of selected sectors. The minimum level of the index which would reflect the full competition is: HHI $\min =100^{2} / \mathrm{nr}$. Companies $=100$

We see from the results obtained that the level of index for the past three years is closer to 100 than 10,000 which indicate a low level of market 
concentration. The annual change rate for the period 2012-2013 is 0.17 times and the annual change rate in 2013-2014 is declining by 0.06 times.

Practically index values would be higher than the values listed in the table because the study assumed a maximum level of value sales for companies that do not appear as large taxpayers. Given that the greater weight of the sector (about 80\%) is dominated by 22 studied companies, theoretical calculated assessment comes close to the actual market value.

\section{Conclusion}

After studying the main elements that characterize the pharmaceutical market in Albania and especially after analyzing the level of competitiveness of the constituent companies, we come to these conclusions.

First, the pharmaceutical market in Albania is a regulated and stable and market. Most of this market currently is dominated by 22 companies that are counted as large tax payers, based on the internal regulations of the General Directorate of Tax. Although entry and exit barriers in the sector are low, the specific characteristics of the activity within this sector show that the number of participating companies is stable over the years.

Second, the generated results indicate a low level of concentration between $0 \%-50 \%$ which reflects a position between perfect competition and oligopoly. Also, from the results obtained from HHI we saw that the level of index for the past three years is closer to 100 than 10,000 which indicate a low level of market concentration.

\section{References:}

(MIDAS), IMS Health. (April 2015). United States of America.

Berman, P. R. (n.d.). "The impoverishing Effect of Healthcare Payments in India: New Methodology and Findings". Economic and Political Weekly, 65. Chaudhuri, S. (2012, March 24). "Multinationals and Monopolies: Pharmaceutical Industry India after TRIPS". Economic and Political Weekly, 47(12).

Chaudhuri, S. (2013, April 27). "The Larger Implications of the NovartisGlivec Judgment". Economic and Political Weekly, 48(17).

European Federation of Pharmaceutical Industries. (n.d.). Retrieved from www.efpia.eu.

Gouri, G. (2009). "Policy Roundtables Generic Pharmaceuticals". OECD, DAF/ COMP (2009).

Instituti i Statistikave. (n.d.). Retrieved from www.instat.gov.al.

Krishna, A. (2010). "One Illness Away: How People Escape Poverty and Why they Become Poor". Oxford University Press.

Market Research, pharmaceutical. (n.d.). Retrieved from www.reportlinker.com. 
Martin, S. (2004). Advanced Industrial Economics, Blackwell.

Nanda, N. a. (2006). "Competition Policy for the Pharmaceuticals Sector in India". Towards a Functional Competiton Policy for India". Academic Foundation in Association with Consumer Unity and Trust Society.

World Health Organisation. (n.d.). Retrieved from www.who.org.

\section{Appendix:}

In Appendix we present a summary of data on which the paper is supported. The data for the first 22 companies are generated by companies' financial statements submitted to the General Tax Directorate. For other companies which are small in this sector, we get the level of estimated sales of 250 million ALL. On these data are calculated CR4 and HHI index.

\begin{tabular}{|c|c|c|c|}
\cline { 2 - 4 } \multicolumn{1}{c|}{} & \multicolumn{3}{|c|}{ Sales per Year } \\
\hline Company & $\mathbf{2 0 1 2}$ & $\mathbf{2 0 1 3}$ & $\mathbf{2 0 1 4}$ \\
\hline 1 & $1,268,085,995$ & $1,103,764,140$ & $1,254,581,516$ \\
\hline 2 & $344,048,351$ & $354,229,566$ & $317,938,134$ \\
\hline 3 & $706,404,503$ & $757,841,196$ & $794,359,536$ \\
\hline 4 & $697,207,449$ & $662,152,997$ & $579,802,147$ \\
\hline 5 & $3,606,166,848$ & $3,799,673,436$ & $3,342,767,360$ \\
\hline 6 & $888,488,169$ & $857,488,717$ & $977,834,903$ \\
\hline 7 & $912,057,913$ & $862,967,569$ & $896,518,571$ \\
\hline 8 & $824,183,453$ & $742,328,748$ & $825,517,343$ \\
\hline 9 & $712,980,398$ & $741,046,868$ & $631,958,374$ \\
\hline 10 & $1,049,141,783$ & $1,139,636,859$ & $948,741,320$ \\
\hline 11 & $2,189,943,698$ & $2,211,792,937$ & $1,816,922,339$ \\
\hline 12 & $853,313,946$ & $748,177,984$ & $912,295,348$ \\
\hline 13 & $835,093,691$ & $1,014,655,452$ & $840,145,508$ \\
\hline 14 & $361,173,463$ & $370,484,984$ & $341,124,840$ \\
\hline 15 & $876,562,627$ & $809,626,348$ & $787,512,056$ \\
\hline 16 & $360,309,564$ & $274,162,715$ & $286,789,620$ \\
\hline 17 & $675,984,407$ & $852,414,300$ & $919,698,371$ \\
\hline 18 & $824,166,421$ & $1,086,531,183$ & $2,102,507,184$ \\
\hline 19 & $2,065,723,559$ & $2,830,864,574$ & $3,034,257,529$ \\
\hline 20 & $256,114,677$ & $263,200,820$ & $346,324,968$ \\
\hline 21 & $482,222,726$ & $386,921,249$ & $296,021,763$ \\
\hline 22 & & $1,084,933,830$ & $1,011,353,479$ \\
\hline Total (ALL) & $\mathbf{2 0 , 7 8 9 , 3 7 3 , 6 4 1}$ & $\mathbf{2 2 , 9 5 4 , 8 9 6 , 4 7 1}$ & $\mathbf{2 3 , 2 6 4 , 9 7 2 , 2 0 9}$ \\
\hline
\end{tabular}




\begin{tabular}{|c|c|c|c|}
\hline \multirow[b]{2}{*}{ Company } & \multicolumn{3}{|c|}{ Sales per Year } \\
\hline & 2012 & 2013 & 2014 \\
\hline 1 & $1,268,085,995$ & $1,103,764,140$ & $1,254,581,516$ \\
\hline 2 & $344,048,351$ & $354,229,566$ & $317,938,134$ \\
\hline 3 & $706,404,503$ & $757,841,196$ & $794,359,536$ \\
\hline 4 & $697,207,449$ & $662,152,997$ & $579,802,147$ \\
\hline 5 & $3,606,166,848$ & $3,799,673,436$ & $3,342,767,360$ \\
\hline 6 & $888,488,169$ & $857,488,717$ & $977,834,903$ \\
\hline 7 & $912,057,913$ & $862,967,569$ & $896,518,571$ \\
\hline 8 & $824,183,453$ & $742,328,748$ & $825,517,343$ \\
\hline 9 & $712,980,398$ & $741,046,868$ & $631,958,374$ \\
\hline 10 & $1,049,141,783$ & $1,139,636,859$ & $948,741,320$ \\
\hline 11 & 2,189,943,698 & 2,211,792,937 & 1,816,922,339 \\
\hline 12 & $853,313,946$ & $748,177,984$ & $912,295,348$ \\
\hline 13 & $835,093,691$ & $1,014,655,452$ & $840,145,508$ \\
\hline 14 & $361,173,463$ & $370,484,984$ & $341,124,840$ \\
\hline 15 & $876,562,627$ & $809,626,348$ & $787,512,056$ \\
\hline 16 & $360,309,564$ & $274,162,715$ & $286,789,620$ \\
\hline 17 & $675,984,407$ & $852,414,300$ & $919,698,371$ \\
\hline 18 & $824,166,421$ & $1,086,531,183$ & $2,102,507,184$ \\
\hline 19 & $2,065,723,559$ & $2,830,864,574$ & $3,034,257,529$ \\
\hline 20 & $256,114,677$ & $263,200,820$ & $346,324,968$ \\
\hline 21 & $482,222,726$ & $386,921,249$ & $296,021,763$ \\
\hline 22 & $250,000,000$ & $1,084,933,830$ & $1,011,353,479$ \\
\hline 23 & $250,000,000$ & $250,000,000$ & $250,000,000$ \\
\hline 24 & $250,000,000$ & $250,000,000$ & $250,000,000$ \\
\hline$\ldots$ & $250,000,000$ & $250,000,000$ & $250,000,000$ \\
\hline$\ldots$ & $250,000,000$ & $250,000,000$ & $250,000,000$ \\
\hline$\ldots$ & $250,000,000$ & $250,000,000$ & $250,000,000$ \\
\hline 98 & $250,000,000$ & $250,000,000$ & $250,000,000$ \\
\hline 99 & $250,000,000$ & $250,000,000$ & $250,000,000$ \\
\hline 100 & $250,000,000$ & $250,000,000$ & $250,000,000$ \\
\hline Total (ALL) & $40,289,373,641$ & $42,454,896,471$ & $42,764,972,209$ \\
\hline
\end{tabular}

